\title{
Totentafel
}

Herr Dr. h. c. Jacques B rodbeck-Sandreuter, Mitglied der Schweiz. Gesellschaft für Geschichte der Medizin und der Naturwissenschaften, ist am 20. Februar dieses Jahres im Alter von 62 Jahren seiner rastlosen, außerordentlich vielseitigen und fruchtbaren Tätigkeit durch den Tod entrissen worden.

Der verehrte Verstorbene hat neben seiner gewaltigen Arbeitslast, welche er als Präsident und Delegierter des Verwaltungsrates der Gesellschaft für Chemische Industrie in Basel bewältigte, noch Zeit gefunden, seiner Liebe zur Medizingeschichte in mannigfacher Weise Ausdruck zu geben. Durch Errichtung der Jacques Brodbeck-Stiftung zur Erforschung der $\mathrm{G}$ e $\mathrm{schi}$ ch te der $\mathrm{M}$ edizin in der Schweiz hat er diesen Bestrebungen ein bleibendes Denkmal gesetzt. Dem gleichen Ziele diente die von ihm initiativ geförderte, ja eigentlich ins Leben gerufene so vielseitig anregende $\mathrm{C}$ i b a $\mathrm{Z}$ e i $\mathbf{t} \mathbf{s} \mathbf{c h} \mathbf{r}$ if $\mathbf{t}$.

Durch den Hinschied von Herrn Dr.h.c. Brodbeck-Sandreuter hat die an den schweizerischen Universitäten wie im sonstigen Geistesleben der Schweiz etwas stiefmütterlich behandelte medizingeschichtliche Forschung, welche in unserm Land über ein besonders reiches und interessantes Material verfügt mit viel ungehobenen Schätzen, die der wissenschaftlichen Bearbeitung harren - einen schweren Verlust erlitten.

Auch der "G e s ne rus» verdankt dem verehrten Verstorbenen hilfreiche Förderung, ohne welche diese junge Zeitschrift den Weg an die Offentlichkeit wohl kaum hätte wagen dürfen. Die Schweiz. Gesellschaft für Geschichte der Medizin und der Naturwissenschaften und die Redaktion des «Gesnerus» werden dem Dahingeschiedenen ein ehrendes Andenken bewahren. H.F.

\section{Leonardo: der Mensch}

E tu uomo, che consideri in questa mia fatica l'opere mirabili della natura, se giudicherai essere cosa nefanda il distruggerla, or pensa essere cosa nefandissima il torre la vita all'omo, del quale, se questa sua compositione ti pare de maraviglioso artifitio, pensa questa essere nulla rispetto all'anima che in tale architettura abita, e veramente, quale essa si sia, ella è cosa divina, sicchè lascia la abitare nella sua opera a suo beneplacito, e non volere che la tua ira o malignità distrugga una tanta vita, che veramente, chi non la stima, non la merita.

\section{Leonardo da Vinci}

auf der Rückseite eines anatomischen Zeichnungsblattes (Richter 1939 II Nr. 1140 p. 238). 